\title{
Optimalisasi sistem pendingin berbasis termoelektrik berpendingin air
}

\section{Optimization of water-cooled thermoelectric-based cooling systems}

\author{
B. A. Girawan*, F. Ariyanto \\ Prodi Teknik Mesin, Jurusan Teknik Mesin, Politeknik Negeri Cilacap, Jln. Dr. Soetomo No.1, \\ Sidakaya, Cilacap, Indonesia. \\ *E-mail: bayuaji.girawan@politeknikcilacap.ac.id
}

ARTICLE INFO ABSTRACT

Article History:

Received 11 September 2018

Accepted 25 September 2018

Available online 1 January 2019

Keywords:

Thermoelectric

solid state heat pump

COP

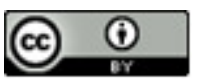

The use of refrigerator and air conditioner in human life causes increase in use of hydrocarbon and fluorocarbon each year. Hydrocarbon and fluorocarbon are hazardous substances that can make a hole in ozone that cause increase in receive of ultraviolet on earth, that will give negative impact on human health. Thermoelectric refrigeration as a solid state heat pump is a safe solution to substitute the used of hydrocarbons and fluorocarbons based refrigerator and air conditioner. The experiment is conducted to test a thermoelectric based refrigeration system which uses water as a working fluid. The result shows that refrigeration system will be optimum at $6 \mathrm{~V}$ and 2.24A of electricity consumption, and 0.5 and 1 litre/minute of water flow rate. While Coefficient of Performance (COP) of the system is 0.86 .

Dinamika Teknik Mesin, Vol. 9, No. 1 Januari 2019, p. ISSN: 2088-088X, e. ISSN: 2502-1729

\section{PENDAHULUAN}

Hidrokarbon merupakan salah satu refrigeran yang banyak digunakan pada sistem pendingin. Hidrokarbon merupakan zat yang berbahaya bagi ozon jika zat tersebut lepas ke atmosfer karena akan mengakibatkan kerusakan pada lapisan ozon di stratosfer yang menyebabkan peningkatan sinar ultraviolet yang diterima oleh manusia di bumi. Paparan sinar ultraviolet yang berlebihan diketahui dapat menyebabkan kanker kulit, katarak pada mata dan berbagai penyakit lainnya (Isnanda, 2005).

Jenis refrigeran lain yang banyak digunakan adalah adalah refrigeran yang mengandung bahan kimia jenis chloro fluoro carbon (CFC) yang didominasi oleh R-12 dan R-22. Maraknya penggunaan CFC karena memiliki sifat stabil, tidak mudah terbakar dan tidak beracun. Namun CFC memiliki ALT (Atmosfer Life Time) yang sangat besar yaitu 1. Artinya gas ini akan bertahan selama 15 tahun di atmosfer sebelum terurai. Dampak langsung dari hal ini adalah kerusakan lapisan ozon yang diperburuk dengan karbondioksida dari kendaraan bermotor sehingga menyebabkan pemanasan global menjadikan efek rumah kaca semakin meningkat (Maulana, 2010).

Tingginya kenaikan pemakaian refrigeran ini menjadi permasalahan jangka panjang yang harus segera dicari solusinya jika melihat dampak terhadap kesehatan dan lingkungan yang ditimbulkannya. 
Salah satu solusi yang dapat dilakukan adalah mengganti sistem refrigerasi yang semula bergantung pada freon sebagai refrigeran dengan pompa kalor padat (solid state heat pump). Pompa kalor padat relatif aman digunakan karena tidak menggunakan cairan ataupun zat kimia yang berbahaya bagi lingkungan serta mudah dalam perawatannya. Hal ini karena pompa kalor padat tidak banyak menggunakan komponen yang bergerak.

Widianto dkk. (2014) melakukan penelitian tentang ujicoba peti ikan berpendingin untuk pedagang ikan keliling. Peti ikan berbentuk kotak dengan volume 33 liter yang mempunyai dinding dalam terbuat dari alumunium dan insulator dari poliuretan. Sistem pendingin dalam peti penyimpanan ikan menggunakan pendingin termoelektrik sebanyak 2 buah, menggunakan heatsink pada sisi dingin dan heatpipe pada sisi panas termoelektrik, memanfaatkan sumber listrik aki sepeda motor bertegangan $12 \mathrm{~V}$ dan arus sebesar 3,5 A. Percobaan diawali dengan pengamatan suhu ruang peti ikan dalam kondisi kosong tanpa ikan yang dilakukan tiap 10 menit selama 2 jam. Dari hasil ujicoba diperoleh temperatur yang dapat dicapai pada peti dalam kondisi kosong mencapai $12^{\circ} \mathrm{C}$ pada 1 jam pertama, kemudian menjadi $11,1^{\circ} \mathrm{C}$ pada 1 jam berikutnya. Temperatur tersebut dicapai pada kondisi suhu lingkungan $27^{\circ} \mathrm{C}$.

Mainil dkk. (2015) melakukan penelitian tentang penggunaan termoelektrik sebagai element pendingin kotak pendingin. Dimensi dari kotak pendingin adalah 13,8 liter, menggunakan 2 buah modul termoelektrik tipe TEC1-12706. Heat exchanger pada sisi dingin dan sisi panas termoelektrik menggunakan tipe heatsink dan kipas. Dari hasil pengujian diperoleh temperatur akhir yang dicapai pada adalah $14.6^{\circ} \mathrm{C}$ dalam waktu 36 menit dengan beban berupa air $2100 \mathrm{ml}$.

Putra dan Repi (2015) melakukan rancang bangun kotak pendingin berbasis termoelektrik untuk penyimpanan vaksin dan obat-obatan. Volume kotak yang akan didinginkan adalah 4,8 liter, menggunakan 4 buah termoelektrik dengan daya total 42 watt. Pengujian dilakukan menggunakan beban berupa urine sebanyak 500, 250 dan $100 \mathrm{ml}$, dengan temperatur akhir yang dicapai pada kotak pendingin dengan beban tersebut secara berturut-turut adalah $18,7,18,7$ dan $18,4^{\circ} \mathrm{C}$. Sedangkan temperatur yang dicapai pada saat kotak tanpa beban adalah sebesar $18,4^{\circ} \mathrm{C}$.

Nulhakim (2017) melakukan penelitian untuk menguji unjuk kerja pendingin ruangan berbasis termolektrik. Alat ini menggunakan 2 buah termoelektrik tipe TEC1-12706 dengan heatsink dan kipas pada sisi dingin dan panas termoelektrik. Pengujian dilakukan selama 30 menit dengan variasi tegangan 3, 6, 9 dan $12 \mathrm{~V}$. Dari hasil pengujian diperoleh hasil alat ini dapat menghasilkan temperatur $20^{\circ} \mathrm{C}$ setelah 30 menit dihidupkan.

Widianto dan Hakim (2016) melakukan penelitian tentang unjuk kerja pendingin peti berbasis termoelektrik. Pendingin yang digunakan adalah termoelektrik dengan heatsink pada sisi dingin dan heatpipe pada sisi panas termolektrik. Unjuk kerja sistem diamati berdasarkan variasi tegangan input 12, 10 dan $8 \mathrm{~V}$. Temperatur peti yang dihasilkan berdasarkan tegangan 12, 10 dan $8 \mathrm{~V}$ secara berturut-turut adalah 14,16 dan $17^{\circ} \mathrm{C}$. Temperatur pada heatsink berdasarkan tegangan 12,10 dan 8 $V$ secara berturut-turut adalah $0,1,3$, dan $4^{\circ} \mathrm{C}$, sedangkan temperatur heatpipe 31,30 dan $27^{\circ} \mathrm{C}$. Kebutuhan arus listrik sistem pendingin pada tegangan 12, 10 dan $8 \mathrm{~V}$ sebesar $6,3,4,8$, dan 3,8 $\mathrm{A}$ sedangkan nilai cooling capacity sebesar 12,5, 10,5 dan 10,5 W.

Wahyu dkk. (2016) melakukan rancang bangun dan pengujian alat pendingin dan pemanas berbasis termoelektrik. Alat ini menggunakan termolektrik dengan spesifikasi daya $63 \mathrm{~W}$ sebanyak 4 buah. Dimensi dari ruangan pendingin ini adalah $100 \mathrm{lt}$, dengan pendingin sisi panas termoelektrik menggunakan air dengan volume $30 \mathrm{It}$, dan sisi dingin termoelektrik menggunakan air dengan volume 2 It. Sirkulasi air pada sisi panas termoelektrik dimanfaatkan sebagai pemanas air. Variabel yang diukur dalam eksperimen ini adalah termperatur air pendingin dan debit pompa untuk menghitung coefficient of performance (COP). Dari hasil pengujian diperoleh cooling capacity yang dihasilkan oleh satu buah termoelektrik adalah sebesar 37 watt dan besarnya COP dari sistem adalah 0,58 . Sistem dapat menghasilkan temperatur sebesar $13^{\circ} \mathrm{C}$ pada menit ke 40 .

Jugsujinda dkk. (2011) melakukan analisa tentang unjuk kerja sebuah lemari pendingin termoelektrik dengan dimensi $25 \times 25 \times 35 \mathrm{~cm}^{3}$. Termoelektrik yang digunakan adalah TEC1-12705. Pengukuran dilakukan pada 10 titik di dalam lemari pendingin. Hasil dari pengukuran menunjukkan temperatur mengalami penurunan dari $30^{\circ} \mathrm{C}$ menjadi $20^{\circ} \mathrm{C}$ dalam waktu 1 jam. Sementara COP dari TEC dan lemari pendingin secara berturut-turut adalah 0,65 dan 3,0. 
Tan dan Zhao (2015) melakukan studi tentang sistem pendingin termoelektrik menggunakan tipe penukar kalor jenis radiator dan shell and tube. Hasil percobaan diperoleh COP untuk jenis radiator dan shell and tube secara berturut-turut adalah 0,5 dan 0,78 .

Mirmanto dkk. (2018) melakukan penelitian tentang unjuk kerja kotak pendingin berbasis termoelektrik. Termoelektrik yang digunakan adalah TEC1-12706, menggunakan pendingin air pada sisi panas termolektrik dengan variasi laju aliran massa 5, 10 dan $15 \mathrm{~g} / \mathrm{s}$. Dari hasil penelitian diperoleh COP pada laju aliran massa 5, 10 dan $15 \mathrm{~g} / \mathrm{s}$ secara berturut-turut adalah 0,017, 0,016, 0,015 .

Ananta dkk. (2017) melakukan penelitian tentang unjuk kerja kulkas termoelektrik dengan rangkaian seri dan paralel pada beban air $1500 \mathrm{ml}$. Dimensi kulkas adalah 40,8 x 32,6 x 53,8 cm, menggunakan 2 buah termoelektrik TEC1-12706 dengan konsumsi daya listrik masing-masing termoelektrik sebesar $12 \mathrm{~W}$. Dari hasil pengujian diperoleh temperatur pada kulkas dengan susunan termoelektrik seri dan paralel secara berturut-turut sebesar 22,54 dan $23,10^{\circ} \mathrm{C}$. Sedangkan COP untuk kulkas dengan susunan seri dan paralel secara berturut-turut adalah 0,45 dan 0,4.

Mirmanto dkk. (2018) melakukan penelitian tentang unjuk kerja kotak pendingin menggunakan pernukar kalor heatsink dan kipas serta heat pipe dengan dua buah kipas. Termoelektrik yang digunakan adalah TEC2-25408. Dari hasil pengujian diperoleh COP tertinggi adalah 0,020 pada konsumsi daya listrik $1,04 \mathrm{~W}$. COP tertinggi dihasilkan oleh sistem pendingin yang menggunakan heat pipe dengan dua buah kipas.

Ismael dkk. (2016) melakukan penelitian tentang disipasi kalor pada radiator. Pada penelitian ini dilakukan pengamatan terhadap perubahan pitch pada fin radiator. Variasi pitch dari fin radiator yang digunakan adalah 2,5, 2,4, 2,3, 2,2 dan 2,1 mm. Dari hasil penelitian diperoleh kesimpulan bahwa pitch yang lebih lebar pada radiator yaitu 2,5 mempunyai kemampuan disipasi kalor yang lebih baik.

Pada penelitian ini akan dilakukan analisis performa sebuah sistem pendingin dengan pompa kalor padat berbasis termolektrik, dengan menggunakan air sebagai fluida kerja. Dari hasil penelitian akan dianalisa Coefficient of Performance (COP) dan temperatur yang optimal dari sistem.

\section{METODE PENELITIAN}

Penelitian ini merupakan penelitian eksperimental dengan skema aparatus seperti terlihat pada gambar 1 dan gambar 2. Sistem pendingin ini menggunakan termolektrik sebagai pompa kalor yang kedua sisinya terhubung dengan dua buah waterblock. Sistem bekerja dengan memanfaatkan air sebagai fluida kerja yang bekerja dalam sistem yang tertutup.

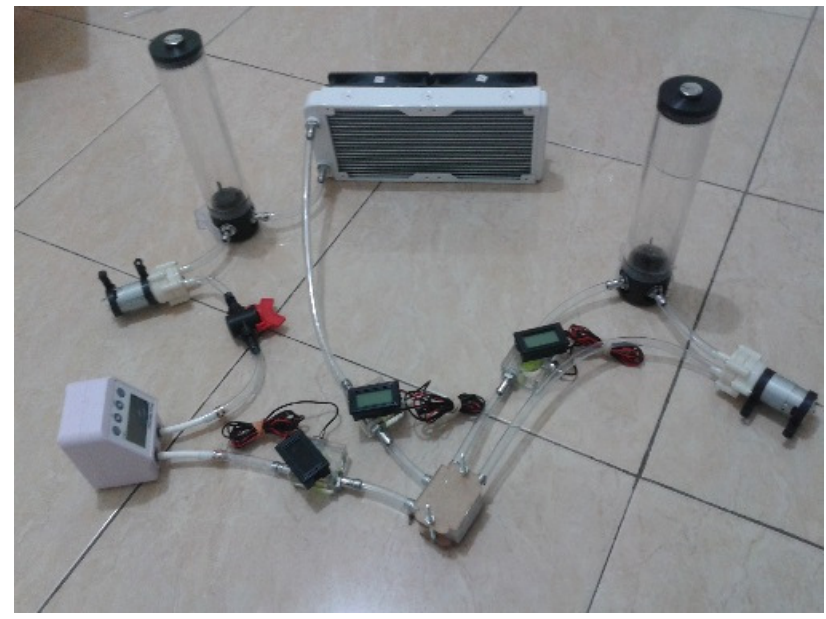

Gambar 1. Foto aparatus penelitian 


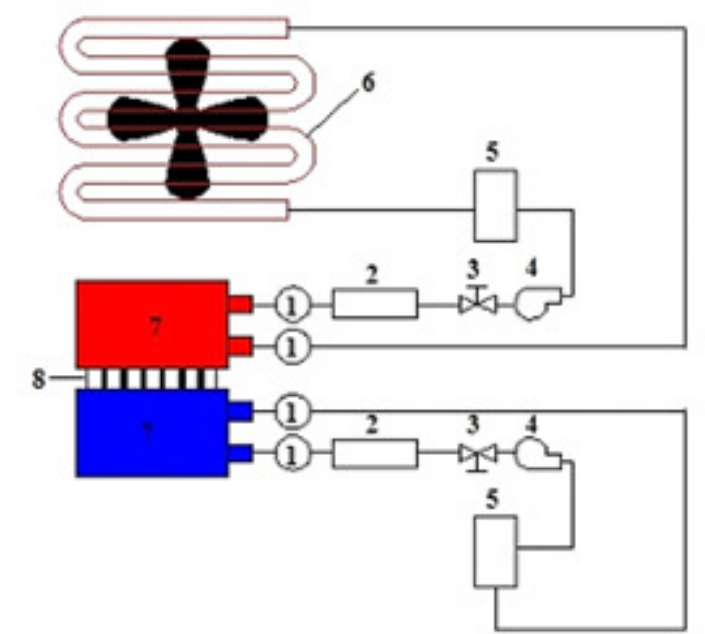

1. Temperatur monitoring, 2. Flowmeter, 3. Kran,

4. Pompa, 5. Reservoir, 6. Radiator, 7. Waterblock,

8. termoelektrik, 9. Keran, 10. Gelas ukur

Gambar 2. Skema aparatus penelitian

Tabel 1. Alat dan bahan

\begin{tabular}{ll}
\hline Nama & Spesifikasi \\
\hline Termoelektrik & TEC1-12706 \\
Radiator & Bahan alumunium, panjang x lebar x tebal = $274 \times 118 \times 311 \mathrm{~mm}$ \\
Pompa & Max 3 liter/menit \\
Flowmeter & $0,8-8$ liter/menit \\
Temperatur monitor & Digital thermometer \\
Stop kran & Model ball valve \\
Waterblock & Alumunium panjang $\times$ lebar $=40 \times 40 \mathrm{~mm}$ \\
Reservoir & Diameter $\times$ tinggi $=50 \times 240 \mathrm{~mm}$ \\
Kipas radiator & Ukuran $120 \times 120 \mathrm{~mm}$ \\
& Tegangan 12 Volt $\mathrm{DC}$
\end{tabular}

Laju perpindahan kalor yang dibuang dari sisi panas termoelektrik melalui radiator dapat dihitung menggunakan persamaan (Cengel dan Ghajar, 2015):

$Q_{h}=m_{c} c_{p h}\left(T_{h o u t}-T_{h i n}\right)$

$Q_{h}$ adalah kalor yang dibuat (watt), $m_{c}$ adalah laju aliran massa $(\mathrm{kg} / \mathrm{s}), C_{p h}$ adalah kalor jenis fluida kerja (J/kgK), $T_{\text {out }}$ adalah temperatur saluran keluar $(\mathrm{K})$ dan $T_{\text {in }}$ adalah temperatur saluran masuk $(\mathrm{K})$. Kapasitas pendingan dari sistem dapat dihitung menggunakan persamaan:

$Q_{c}=m_{c} c_{p c}\left(T_{\text {cout }}-T_{\text {cin }}\right)$ 
$Q_{c}$ adalah kapasitas pendinginan (watt), mc adalah laju aliran massa $(\mathrm{kg} / \mathrm{s}), C_{p c}$ adalah kalor jenis fluida kerja $(\mathrm{J} / \mathrm{kgK}), T_{\text {cout }}$ adalah temperatur saluran keluar sisi panas termoelektrik $(\mathrm{K})$, dan $T_{\text {cin }}$ adalah temperatur saluran masuk sisi dingin termoelektrik (K).

Besarnya laju aliran massa dapat dihitung menggunakan persamaan:

$m_{c}=\frac{\rho Q}{60}$

$\rho$ adalah massa jenis fluida kerja ( $\mathrm{kg} / \mathrm{liter})$ dan $Q$ adalah debit aliran fluida kerja (liter/menit). Sedangkan unjuk kerja sistem pendingin (COP) dapat dihitung menggunakan persamaan:

$C O P=\frac{Q_{c}}{Q_{h}}$

$Q_{c}$ adalah apasitas pendinginan (watt), dan $Q_{h}$ adalah laju perpindahan kalor sisi panas termoelektrik (watt).

Pada pengujian akan dilakukan beberapa variasi berupa debit aliran dan tegangan. Debit aliran air yang divariasikan adalah debit aliran pada sisi panas termoelektrik. Adapun variasi debit aliran yang digunakan adalah 0,5, 1 dan 1,5 liter per menit (LPM). Pengaturan debit aliran air dilakukan melalui pengaturan stop kran. Variasi tegangan dilakukan pada termoelektrik dengan mengikuti standar tegangan adaptor yang tersedia di pasaran yaitu 6, 9 dan 12 volt. Pada eksperimen ini digunakan adjustable power supply untuk suplai listrik pada termoelektrik. Volume air yang digunakan pada sisi panas dan dingin adalah 0,3 liter. Temperatur diukur tiap 5 menit selama 30 menit. Pengaturan lain yang dilakukan pada aparatus berupa kipas radiator dan pompa air. Kecepatan kipas radiator diatur konstan, mengikuti spesifikasi kipas dengan tegangan $12 \mathrm{~V}$ DC. Posisi kipas pada radiator adalah posisi menghisap. Tegangan yang digunakan pada pompa air adalah $12 \mathrm{~V} D C$, dengan arus 0,5 ampere. Tegangan yang digunakan di atur konstan.

\section{HASIL DAN PEMBAHASAN}

Besarnya arus listrik pada penggunaan tegangan 6,9 dan $12 \mathrm{~V}$ termoelektrik dapat dilihat pada tabel 2.Temperatur pada sisi dingin pada tegangan $6 \mathrm{~V}$ dapat dilihat pada gambar 3 . Pada tegangan $6 \mathrm{~V}$, temperatur sisi dingin pada menit ke-30 dengan debit aliran 0,5, 1 dan 1,5 liter/menit secara berturut-turut adalah sebesar $22,5,23,1$ dan $23,4^{\circ} \mathrm{C}$. Dari hasil pengujian menunjukkan debit aliran fluida kerja radiator sebesar 0,5 liter/menit menghasilkan temperatur pendinginan terendah yaitu $22,5^{\circ} \mathrm{C}$.

Tabel 2. Arus dan tegangan listrik.

\begin{tabular}{cc}
\hline Tegangan $(\mathrm{V})$ & Arus $(\mathrm{A})$ \\
\hline 6 & 2,24 \\
9 & 3,23 \\
12 & 4,09 \\
\hline
\end{tabular}

Hal ini berarti pada debit aliran 0,5 liter/menit, radiator dapat membuang panas lebih baik dibanding dengan debit aliran 1 dan 1,5 liter/menit. Pada tegangan 9V, temperatur sisi dingin pada menit ke-30 dengan debit aliran 0,5, 1 dan 1,5 liter/menit secara berturut-turut adalah sebesar 21,8, 22,8 dan $22,8^{\circ} \mathrm{C}$. Temperatur terendah dicapai oleh sistem dengan debit aliran 0,5 liter/menit yaitu $21,8^{\circ} \mathrm{C}$.

Pada tegangan $12 \mathrm{~V}$, temperatur sisi dingin pada menit ke-30 dengan debit aliran $0,5,1$ dan 1,5 liter/menit secara berturut-turut adalah sebesar $22,4,22,9$ dan $22,8^{\circ} \mathrm{C}$. Temperatur terendah dicapai oleh sistem dengan debit aliran 0,5 liter/menit. Secara keseluruhan, sistem pendingin yang paling optimal jika dilihat dari temperatur terendah yang dapat dicapai adalah pada tegangan $9 \mathrm{~V}$ dengan 
debit aliran radiator sisi panas 0,5 liter/menit. Namun demikian, perbedaan temperatur akhir pada 30 menit tidak signifikan. Unjuk kerja sistem pendingin (COP) berdasarkan tegangan dan debit aliran fluida kerja radiator dapat dilihat pada gambar 6 .

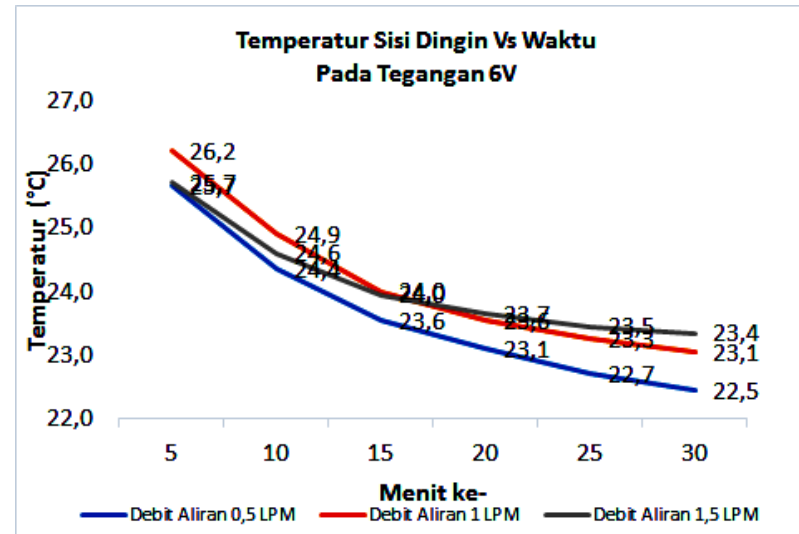

Gambar 3. Temperatur sisi dingin pada tegangan $6 \mathrm{~V}$

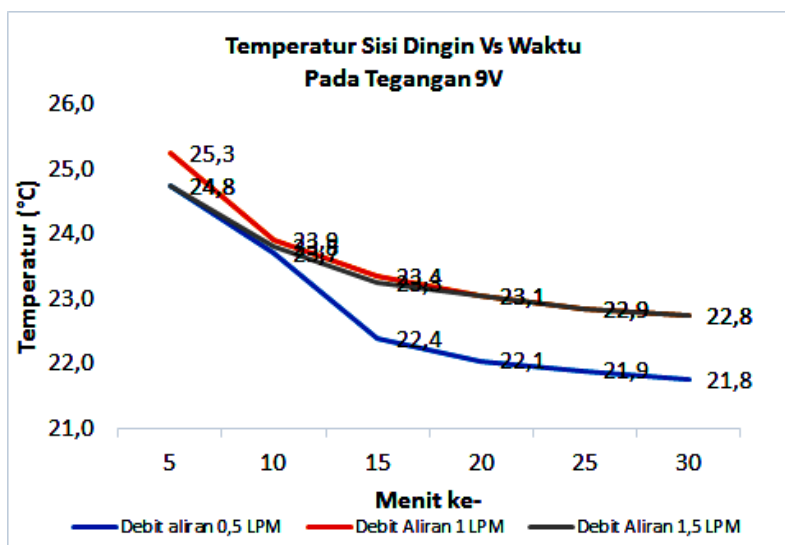

Gambar 4. Temperatur sisi dingin pada tegangan 9V

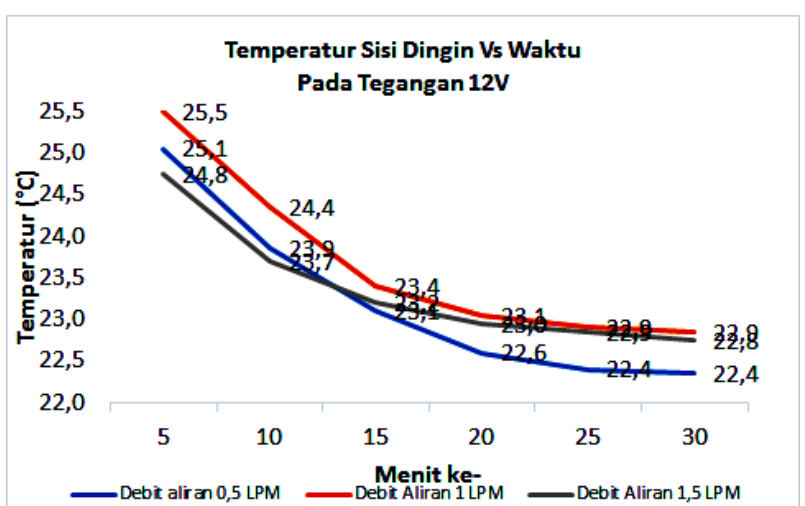

Gambar 5. Temperatur sisi dingin pada tegangan 12V

Sistem pendingin yang bekerja pada tegangan $6 \mathrm{~V}$ memiliki performa yang paling tinggi dibandingkan pada tegangan 9 dan $12 \mathrm{~V}$. Secara keseluruhan, debit aliran fluida juga sangat mempengaruhi COP. Sistem dengan debit aliran fluida kerja 0,5 dan 1 liter/menit mempunyai COP 
yang sama pada tegangan 6 dan 12V. Namun pada tegangan 9V debit aliran 0,5 liter/menit mempunyai COP yang lebih tinggi dibandingkan debit aliran 1 liter/menit dengan perbedaan yang tidak signifikan. Sehingga secara keseluruhan, sistem dengan debit aliran fluida kerja $0,5 \mathrm{liter} / \mathrm{menit}$ mempunyai kinerja yang lebih baik, yang ditunjukkan dengan COP yang paling tinggi dibandingkan dengan debit aliran 1 dan 1,5 liter/menit.

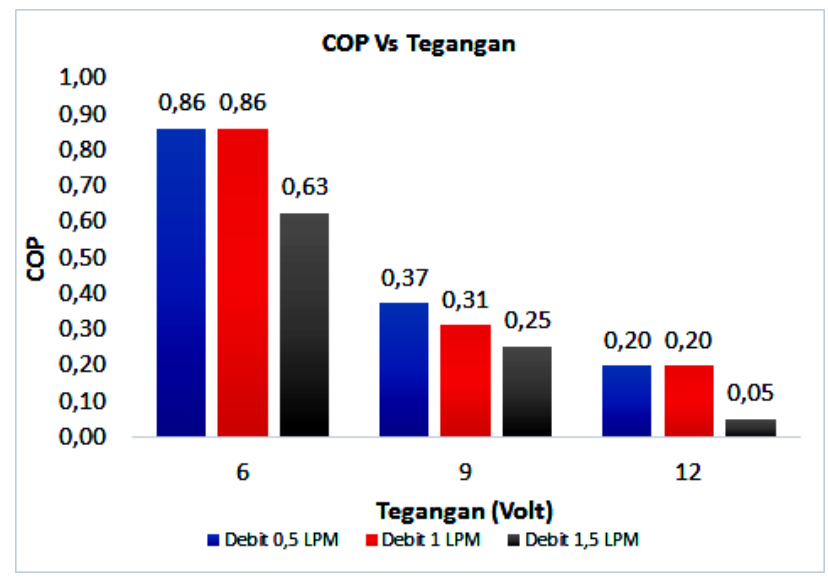

Gambar 6. COP sistem pendingin

\section{KESIMPULAN}

Dari hasil eksperimen yang telah dilakukan diperoleh beberapa kesimpulan yaitu Berdasarkan tegangan yang digunakan pada termoelektrik, sistem pendingin yang menghasilkan temperatur paling rendah adalah sistem dengan tegangan 9V. Sedangkan sistem yang menghasilkan COP yang paling tinggi adalah sistem dengan tegangan 6V. Berdasarkan debit aliran fluida kerja radiator yang digunakan, sistem pendingin yang menghasilkan temperatur paling rendah dan COP paling tinggi pada tegangan $6 \mathrm{~V}, 9 \mathrm{~V}$ dan $12 \mathrm{~V}$ secara berturut-turut adalah pada debit aliran fluida kerja 0,5 dan 1 liter/menit, 0,5 liter/menit dan 0,5 dan 1 liter/menit.

\section{UCAPAN TERIMAKASIH}

Penulis pada kesempatan ini mengucapkan terimakasih kepada semua pihak yang telah membantu baik berupa materi maupun pikiran sehingga penelitian dan paper ini dapat terselesaikan. Yang kedua penulis mengucapkan terimakasih kepada Kemenristekdikti atas bantuan dana penelitian melalui program penelitian hibah internal 2018 yang dibiayai melalui DIPA Politeknik Negeri Cilacap. Yang ke tiga penulis mengapresiasi Jurusan Teknik Mesin di Politeknik Negeri Cilacap atas fasilitas yang dipergunakan dalam penelitian ini.

\section{DAFTAR PUSTAKA}

Ananta H., Padang Y.A., Mirmanto, 2017, Unjuk kerja kulkas termoelektrik dengan rangkaian seri dan paralel pada beban air $150 \mathrm{ml}$, Jurnal Dinamika Teknik Mesin, 7(2), 80-86.

Cengel Y.A., Ghajar A.J., 2015, Heat and mass transfer, Penerbit McGraw-Hill Education, New York.

Ismael T., Yun S.B., Ulugbek F., 2016, Radiator heat dissipation performance, Jurnal of Electronics Cooling and Thermal Control, 6, 88-96.

Isnanda, 2005, Penggunaan Refrigeran hidrokarbon (HC) dalam bisnis perawatan dan perbaikan AC, Jurnal Teknik Mesin, 2(1), 44-48.

Jugsujinda S., Vora-Ud, Seetawan T., 2011, Analyzing of thermoelectric refrigerator performance, Jurnal Procedia Engineering, 8(1), 154-149.

Mainil R.I., Aziz A., Kuniawan A., 2015, Penggunaan modul thermoelekctric sebagai elemeen pendingin box cooler, Prosiding Seminar Nasional Rekayasa dan Aplikasi Teknik Mesin di Industri, Bandung. 
Maulana A., 2010, Penggunaan BPO (Bahan Perusak Ozon) di Provinsi Jakarta dari sektor refrigerator, Jakarta

Mirmanto, Alit I.B., Sayoga I.M.A., Sutanto R., Nurchayati, Mulyanto A., 2018, Experimental cooler box performance using two different heat removal units: A heat sink fin-fan, and a double fan heat pipe, Jurnal Frontiers in Heat and Mass Transfer, 10, 1-7.

Mirmanto, Sutanto R., Putra D.K., 2018 Unjuk kerja kotak pendingin termoelektrik dengan variasi lajua aliran massa air pendingin, Jurnal Teknik Mesin, 7(1), 44-49.

Nulhakim, 2017, Uji unjuk kerja pendingin ruangan berbasis theroelectric cooling, Jurnal Simeteris, 8(1), 85-90.

Putra F.C., Repi V.V.R, 2015, Perancangan dan pembuatan kotak pendingin berbasis termoelektrik untuk aplikasi penyimpanan vaksin dan obat-obatan, Jurnal IImiah Giga, 18(2), 102-109.

Tan G., Zhao D., 2015, Study of thermoelectric space cooling system integrated with phase change material, Jurnal Applied Thermal Engineering, 86, 187-198.

Wahyu D., Andriyanto, Hanif, Sukma R., Rosa Y., 2016, Kajian eksperimental alat multifungsi bercatu daya termoelektrik, Jurnal Rotor, Edisi khusus(2), 46-51.

Widianto T.N., Hakim A.R., 2016, Performansi pendingin termoelektrik alat transportasi ikan segar pada berbagai tegangan, Jurnal Agritech, 36(4), 485-490.

Widianto T.N., Hermawan W., Utomo B.S.B., 2014, Uji coba peti ikan segar berpendingin untuk pedagang ikan keliling, Jurnal JPB Perikanan, 9(2), 185-191. 